\title{
Effect of Erythropoietin Administration on Myocardial Viability and Coronary Microvascular Dysfunction in Anterior Acute Myocardial Infarction: Randomized Controlled Trial in the Japanese Population
}

\author{
Makoto Orii · Kumiko Hirata $\cdot$ Kazushi Takemoto · Takashi Akasaka
}

Received: July 27, 2018 / Published online: October 23, 2018

(C) The Author(s) 2018

\section{ABSTRACT}

Introduction: Cardioprotective effects of erythropoietin (EPO) on infarcted myocardium in acute myocardial infarction (AMI) patients have been inconclusive. This study aimed to assess the effect of EPO administration on coronary microvascular dysfunction (CMD) and myocardial viability in anterior AMI. We also evaluated the serial changes in CMD and cardiac remodeling in these patients.

Methods: Patients with a successful percutaneous coronary intervention (PCI) for the first anterior AMI were randomly assigned to two

Enhanced digital features To view enhanced digital features for this article go to https://doi.org/10.6084/ m9.figshare.7165579.

Electronic supplementary material The online version of this article (https://doi.org/10.1007/s40119018-0122-1) contains supplementary material, which is available to authorized users.

\section{Orii}

Department of Radiology, Iwate Medical University, Morioka, Japan

K. Hirata $(\bowtie)$

Division of Medical Science, Department of Education, Osaka Educational University, Osaka, Japan

e-mail: hiratak@cc.osaka-kyoiku.ac.jp

K. Takemoto $\cdot$ T. Akasaka

Department of Cardiovascular Medicine, Wakayama

Medical University, Wakayama, Japan groups (EPO and control groups), and given single-dose intravenous administration of recombinant human EPO (12,000 IU) or saline after PCI. Delayed-enhanced cardiac magnetic resonance imaging was performed at 1 week after AMI to assess the average of transmural extent of infarction and infarct size. Coronary flow velocity reserve (CFVR) of the left anterior descending coronary artery was measured by Doppler echocardiography at 1 week, 1 month, and 8 months after AMI. All patients underwent clinical follow-up for the assessment of cardiac remodeling.

Results: Sixty-one patients (EPO 32, control 29) were eligible for analysis. EPO group $(2.4 \pm 1.2)$ had a tendency of smaller transmural extent of infarction than that of control group $(2.9 \pm 1.1$; $p=0.063)$. CFVR-8 months improved significantly in EPO group $(2.9 \pm 0.6)$ compared to control group $(2.6 \pm 0.5 ; p=0.04)$. Left atrial (LA) volume -8 months was significantly lower in EPO group $(47 \pm 11)$ than those of control group (65 $\pm 20 ; p=0.004)$.

Conclusions: A single medium dose of EPO could have a favorable effect on CMD and LA remodeling in the chronic phase of anterior AMI.

Trial Registration: The institutional ethics committee of Wakayama Medical University, identifier, 1125. 
Keywords: Acute myocardial infarction; Coronary microvascular dysfunction; Erythropoietin; Myocardial viability

\section{INTRODUCTION}

The loss of myocardial tissue after acute myocardial infarction (AMI) leads to impairment of myocardial contractile function and left ventricular (LV) remodeling [1]. Although prompt reperfusion is highly recommended following AMI for attenuating myocardial damages, reperfusion itself could cause additional lethal injury. This adverse phenomenon known as ischemia-reperfusion injury contributes infarct size and LV remodeling [2, 3]. New strategies that directly target the reperfusion phase could improve subsequent outcome after AMI.

Erythropoietin (EPO) is the main hormone that regulates erythropoiesis. Beyond its wellknown hematopoietic action, EPO has diverse cellular effects in non-hematopoietic tissues [4-6]. Numerous experimental data had reported the cardioprotective effects of EPO in infarcted heart. In these investigations, EPO was associated with significant reduction of myocardial fibrosis and improvements in LV function that were partly attributed to its antiapoptotic and angiogenic properties [7-9]. These findings are not supported by recent clinical trials designed to investigate the efficacy of EPO in AMI patients [10, 11]. Administration of EPO is also associated with higher rates of adverse cardiovascular events in these trials [10]. However, the percentage of anterior AMI is below 50\% in these trials. Anterior AMI is more strongly affected by ischemia-reperfusion injury simply because it perfuses a larger myocardial territory. Moreover, there has been no data about the effect of EPO on coronary microvascular dysfunction (CMD) in anterior AMI patients.

We aimed to assess the effect of a single intravenous bolus of EPO on CMD and myocardial viability in anterior AMI patients. We also evaluated the serial changes in CMD and cardiac remodeling in these patients.

\section{METHODS}

\section{Patients}

We had prospectively enrolled first-time anterior AMI patients between October 2012 and January 2014 at the Wakayama Medical University Hospital. To be included, the patients had to have a first-time AMI with achieving reperfusion of the left anterior descending (LAD) coronary artery within $24 \mathrm{~h}$ of symptom onset. Seventy-five patients with $\geq 2$ grade Thrombosis In Myocardial Infarction (TIMI) flow after successful PCI were randomized into the EPO or control group. Exclusion criteria were persistent severe heart failure (Killip class III or IV), cardiogenic shock, previous MI, multivessel disease, age $>85$ years, blood pressure $>140 / 90 \mathrm{mmHg}$ at the time of administration of EPO, advanced renal (Cre $\geq 2 \mathrm{mg} / \mathrm{dl}$ ) and hepatic (T-Bil $\geq 3 \mathrm{mg} / \mathrm{dl}$ ) dysfunction, and a hematocrit level $>55 \%$ in female or $>60 \%$ in male patients after PCI. Among 75 patients referred for possible enrollment into this study, 14 were excluded: six had severe heart failure or cardiogenic shock and five were found to have a clinical history of prior myocardial infarction. Three patients were also excluded because of advanced renal failure. The remaining 61 patients fulfilled the study criteria.

\section{Study Protocol}

The study was a prospective, randomized, single-blind, placebo-controlled single-center trial. All procedures performed in studies involving human participants were in accordance with the institutional ethics committee of Wakayama Medical University and with the 1964 Helsinki Declaration and its later amendments or comparable ethical standards. Informed consent was obtained from all individual participants included in the study. Trial registration: The institutional ethics committee of Wakayama Medical University, identifier, 1125. The patients were randomized by a blinded independent statistician, and the study processes were not blinded after randomization. 
The patients in the EPO group received a single intravenous administration of $100 \mathrm{ml}$ saline mixed with EPO 12,000 IU (epoetin-beta, Chugai Pharmaceutical, Japan) at the end of PCI. The patients in the control group were injected intravenously with $100 \mathrm{ml}$ saline. All the patients were given heparin intravenously (10,000-15,000 U/day) according to the standard protocol. Optimal standard treatment included administration of $\beta$-blocker, angiotensin-converting enzyme inhibitor, angiotensin II blocker, calcium antagonist, aspirin, clopidogrel, and lipid-lowering therapy. Plasma levels of vascular endothelial growth factor (VEGF) were measured at 1 week after the administration of EPO. Delayed-enhanced cardiac magnetic resonance imaging (DEMRI) was performed at 1 week after AMI to assess the transmural extent of infarcted myocardium and infarct size. Two-dimensional and Doppler echocardiography was performed at 1 week, 1 month, and 8 months after AMI to assess serial changes in cardiac remodeling and CMD of the LAD. All patients underwent clinical follow-up visits every 3 months after enrollment and were assessed for clinical status, safety, adverse reactions, and medication.

\section{Echocardiography}

Transthoracic echocardiography was performed using a Vivid E9 System (GE Healthcare, Horten, Norway) equipped with a $2.5-\mathrm{MHz}$ transducer. Parasternal long- and short-axis views at the basal, midventricular, and apical levels, as well as three standard apical views, were acquired from three consecutive beats (frame rate: 56-92 frames/s). LV ejection fraction (EF) and left atrial (LA) volume were calculated by the biplane modified Simpson' s method. LV mass was estimated by the two-dimensional arealength method.

Coronary flow velocity reserve (CFVR) is dependent on the combined effects of epicardial coronary stenosis and microvascular dysfunction $[3,12,13]$. For coronary flow study, we administered adenosine triphosphate $(0.14 \mathrm{mg} /$ $\mathrm{kg} / \mathrm{min}$ ) intravenously for $2 \mathrm{~min}$ after the baseline coronary flow velocity $(\mathrm{CFV})$ of the $\mathrm{LAD}$ was recorded. This allowed us to obtain the peak flow response induced by coronary microvessel dilatation. During examination, blood pressure and heart rate were recorded every minute. CFVs were recorded at the baseline and during hyperemia and averaged over five cardiac cycles. CFVR was defined as the ratio of mean diastolic CFV during hyperemia to that at the baseline $[12,13]$. All measurements were performed by the experienced investigator who was blinded to all other data using EchoPAC 6.1; GE Healthcare, Horten, Norway. To assess the reproducibility of CFVR, the CFV measurements at base and during hyperemia were repeated 1 day later in randomly assigned 20 patients. The intra- and interobserver variability for the CFVR measurement were $4.3 \pm 3.5 \%$ and $4.2 \pm 3.6 \%$, respectively.

\section{Delayed-enhanced Cardiac Magnetic Resonance Imaging}

Cardiac MRI were performed with a 1.5 -T clinical scanner (Intera Achieva, Philips Medical Systems, Best, The Netherlands) equipped with a five-element cardiac phased-array coil for signal reception, as previously described [14]. Breath-hold cine steady-state free precession images with a time resolution of $35 \mathrm{~ms}$ were acquired. Then, the late enhanced images were obtained by a breath-hold three-dimensional turbo gradient echo with inversion recovery. Ten minutes after intravenous injection of $0.1 \mathrm{mmol} / \mathrm{kg}$ Gd-DTPA (Magnevist, Schering AG, Berlin, Germany), contiguous short-axis slices and representative long-axis slices of the LV were obtained. Scan parameters were as follows: repetition time, $4.1 \mathrm{~ms}$; echo time, $1.25 \mathrm{~ms}$; flip angle, $15^{\circ}$; field of view, $350 \times 350 \mathrm{~mm}$; partial echo; matrix, $224 \times 256$; and spatial resolution, $1.56 \times 2.24 \times 10 \mathrm{~mm}^{3}$ reconstructed to $0.68 \times 0.68 \times 5 \mathrm{~mm}^{3}$. All images were acquired during breath-hold at end expiration. The inversion time was optimized (200 to $300 \mathrm{~ms}$ ) to null the normal myocardium.

All analyses were performed using a dedicated cardiac software package (View Forum, Philips, The Netherlands) for further analysis as 
described previously [14]. Myocardial segments were analyzed for the presence of hyperenhancement, defined after setting of the threshold of $\geq 5$ standard deviations above the mean signal intensity of the remote, normal myocardium in the same slice by the software [15]. Normal myocardium was defined by the absence of any regional contrast enhancement and the combination of normal regional wall thickening. Based on the extent of hyperenhancement, a hyperenhancement category was determined for each segment on a five-point scale: $0 \%$ hyperenhancement (grade 0), 1-25\% hyperenhancement (grade 1), 26-50\% hyperenhancement (grade 2), 51-75\% hyperenhancement (grade 3), 76-100\% hyperenhancement (grade 4) [16]. Then, the total myocardial area and the contrast-enhanced area were traced manually. The total infarct size was calculated, which was defined as the percentage of contrast-enhanced area of the total myocardial area (Area hyperenhancement/ Area $_{\text {myocardium }} \times 100$ ). Microvascular obstruction (MVO) was defined as hypoenhanced regions within the hyperenhanced infarcted area and was included in the calculation of total infarct size [3].

\section{Statistical Analysis}

All statistical analyses were performed using SPSS version 11.0.1 (SPSS Inc., Chicago, IL, USA). Continuous variables are expressed as mean \pm standard deviation, and differences between groups were compared with the Student's $t$ test for normally distributed variables and the Mann-Whitney test for non-normally distributed variables. The Chi-square test was used for categorical variables and Fisher's exact test for categorical variables with low frequencies (expected cell count $<5$ ). Comparisons of the time course of the change between groups were performed using two-way ANOVA. Comparisons of other data between groups were performed using one-way ANOVA. If statistical significance was found for a group, a time effect, or a group-by-time interaction, further comparisons were made with Tukey-Kramer post hoc test between all possible pairs of two groups at individual time points. All tests were twosided and values of $p<0.05$ were considered statistically significant.

\section{RESULTS}

\section{Patient Characteristics}

The clinical baseline characteristics of the 32 EPO and 29 control patients are shown in Table 1. There was no significant difference between the groups in age, sex, incidence of coronary risk factors, re-perfusion time, door-toballoon time, peak creatine kinase, infarct location, TIMI flow grade after PCI, and VEGF. A list of the medications at the onset of AMI is also shown in Table 1 . All the patients in both groups underwent successful implantation of drug eluting stents. There was no significant difference about concomitant therapy between the two groups.

\section{Effect of EPO on Myocardial Viability}

The results of DEMRI at 1 week after AMI are shown in Table 2. EPO group had a tendency of smaller transmural extent of infarction than that of control group $(2.4 \pm 1.2$ and $2.9 \pm 1.1$, $p=0.063)$. There was no significant difference in infarct size and incidence of MVO between the two groups (Table 2).

\section{Effect of EPO on Coronary Circulation}

Table 3 shows the result of Doppler echocardiographic measurements and patient's condition. Regarding hemodynamic measurements, there were no significant differences in heart rate and BP between the two groups and among three phases. Figure 1 demonstrates the change of CFVR in the two groups. CFVR at 1 week after AMI was similar between the two groups $(2.1 \pm 0.5$ and $1.9 \pm 0.4, p=0.122)$. Mean diastolic velocity during hyperemia and CFVR was gradually improved during follow-up period (Table 3). CFVR at 1 and 8 months after AMI was significantly higher than those at 1 week in EPO and control groups (Fig. 1). CFVR at 
Table 1 Baseline clinical characteristics

\begin{tabular}{|c|c|c|c|}
\hline & EPO $(n=32)$ & Control $(n=29)$ & $p$ value \\
\hline Age, years & $68 \pm 12$ & $71 \pm 11$ & 0.309 \\
\hline Men, $n(\%)$ & $26(81 \%)$ & $23(79 \%)$ & 0.849 \\
\hline $\mathrm{BMI}, \mathrm{kg} / \mathrm{m}^{2}$ & $23 \pm 2$ & $22 \pm 3$ & 0.212 \\
\hline Diabetes mellitus, $n(\%)$ & $8(25 \%)$ & $5(17 \%)$ & 0.46 \\
\hline Hypertension, $n$ (\%) & $21(66 \%)$ & $16(55 \%)$ & 0.404 \\
\hline Hypercholesterolemia, $n$ (\%) & $12(38 \%)$ & $6(21 \%)$ & 0.151 \\
\hline Re-perfusion time, min & $358 \pm 239$ & $400 \pm 235$ & 0.389 \\
\hline Door to balloon time, $\min$ & $78 \pm 12$ & $77 \pm 11$ & 0.431 \\
\hline Peak creatine kinase, U/1 & $2749 \pm 1912$ & $2233 \pm 1480$ & 0.261 \\
\hline \multicolumn{4}{|l|}{ Infarct location } \\
\hline Proximal left ascending descending artery, $n(\%)$ & $15(47 \%)$ & $16(55 \%)$ & 0.873 \\
\hline \multicolumn{4}{|l|}{ Concomitant therapy, $n(\%)$} \\
\hline ACE-I/ARB & $9(28 \%)$ & $9(31 \%)$ & 0.804 \\
\hline Beta-receptor blockers & $2(6 \%)$ & $1(3 \%)$ & 0.537 \\
\hline Statin & $7(22 \%)$ & $4(14 \%)$ & 0.412 \\
\hline TIMI flow grade after PCI $2 / 3$ & $7 / 25$ & $5 / 24$ & 0.649 \\
\hline Vascular endothelial growth factor $(\mathrm{pg} / \mathrm{ml})$ & $41 \pm 24$ & $35 \pm 27$ & 0.222 \\
\hline
\end{tabular}

$A C E-I$ angiotensin converting enzyme inhibitor, $A R B$ angiotensin II receptor blocker, TIMI thrombolysis in myocardial infarction, EPO erythropoietin

Table 2 Delayed-enhanced cardiac magnetic resonance imaging parameters

\begin{tabular}{llll}
\hline & EPO $(n=32)$ & Control $(n=29)$ & $16 \pm 9$ value \\
\hline Infarct size (\%) & $19 \pm 12$ & \\
Delayed enhancement category & & 0.399 \\
Grade $0, n(\%)$ & $2(6 \%)$ & $3(10 \%)$ \\
Grade 1, $n(\%)$ & $5(16 \%)$ & $8(28 \%)$ \\
Grade 2, n(\%) & $12(37 \%)$ & $6(21 \%)$ \\
Grade 3, $n(\%)$ & $5(16 \%)$ & $12(41 \%)$ \\
Grade 4, $n(\%)$ & $8(25 \%)$ & $2.9 \pm 1.1$ \\
Average & $2.4 \pm 1.2$ & $9(31 \%)$ \\
Microvascular obstruction, $n(\%)$ & $5(16 \%)$ & 0.063 \\
\hline
\end{tabular}

EPO erythropoietin 
Table 3 Doppler echocardiographic measurements

\begin{tabular}{|c|c|c|}
\hline & $\operatorname{EPO}(n=32)$ & Control $(n=29)$ \\
\hline \multicolumn{3}{|c|}{ Heart rate b.p.m. (Baseline/ATP infusion) } \\
\hline 1 week & $65 \pm 9 / 68 \pm 11$ & $64 \pm 10 / 66 \pm 11$ \\
\hline 1 month & $67 \pm 12 / 70 \pm 12$ & $73 \pm 21 / 68 \pm 10$ \\
\hline 8 months & $64 \pm 11 / 66 \pm 11$ & $63 \pm 10 / 65 \pm 9$ \\
\hline \multicolumn{3}{|c|}{ Systolic blood pressure, $\mathrm{mmHg}$ (Baseline/ATP infusion) } \\
\hline 1 week & $106 \pm 15 / 105 \pm 13$ & $111 \pm 21 / 111 \pm 20$ \\
\hline 1 month & $110 \pm 17 / 108 \pm 16$ & $115 \pm 21 / 115 \pm 20$ \\
\hline 8 months & $113 \pm 17 / 111 \pm 16$ & $118 \pm 13 / 116 \pm 13$ \\
\hline \multicolumn{3}{|c|}{ Diastolic blood pressure, $\mathrm{mmHg}$ (baseline/ATP infusion) } \\
\hline 1 week & $59 \pm 10 / 57 \pm 11$ & $60 \pm 13 / 60 \pm 13$ \\
\hline 1 month & $61 \pm 10 / 59 \pm 9$ & $63 \pm 12 / 62 \pm 12$ \\
\hline 8 months & $62 \pm 11 / 61 \pm 10$ & $65 \pm 9 / 65 \pm 9$ \\
\hline \multicolumn{3}{|c|}{ Mean diastolic velocity, cm/s (baseline/ATP infusion) } \\
\hline 1 week & $20 \pm 7 / 42 \pm 16$ & $19 \pm 7 / 37 \pm 19$ \\
\hline 1 month & $18 \pm 4 / 46 \pm 15$ & $18 \pm 5 / 47 \pm 18$ \\
\hline 8 months & $17 \pm 4 / 48 \pm 13$ & $18 \pm 5 / 46 \pm 19$ \\
\hline \multicolumn{3}{|c|}{ Coronary flow velocity ratio } \\
\hline 1 week & $2.1 \pm 0.5^{\dagger \S}$ & $1.9 \pm 0.4^{+s}$ \\
\hline 1 month & $2.6 \pm 0.5$ & $2.6 \pm 0.5$ \\
\hline 8 months & $2.9 \pm 0.6^{\oplus}$ & $2.6 \pm 0.5$ \\
\hline
\end{tabular}

$A T P$ adenosine triphosphate, $E P O$ erythropoietin

${ }^{\dagger} p=0.0002$ versus 1 month, ${ }^{\dagger} p<0.0001$ versus 1 months, ${ }^{\$} p<0.0001$ versus 8 months, ${ }^{\circ} p=0.039$ versus control

8 months after AMI was significantly higher in EPO group $(2.9 \pm 0.6)$ than those of control group (2.6 $\pm 0.5, p=0.039$ ) (Fig. 1). Figure 2 shows representative images of CFVR and DEMRI after AMI in patients with and without the administration of EPO.

\section{Effect of EPO on Cardiac Remodeling}

The echocardiographic measurements of EPO and control groups are shown in Supplemental
Table 1 and Fig. 3. LV diameter, volume, LVEF, LV mass index, and LA volume at 1 week after AMI were similar between the two groups. In EPO group, LVEF at 8 months after AMI $(53 \pm 7)$ was significantly higher than those at 1 week (48 $\pm 7, p=0.041$ ) (Fig. 3). LA volume at 8 months after AMI was significantly lower in EPO group $(47 \pm 11)$ than those of control group (65 $\pm 20, p=0.004)$ (Fig. 3$)$.

\section{Safety Analysis}

Supplemental Table 2 lists the blood cell count in peripheral blood during follow-up period. The peak of $\mathrm{RBC}, \mathrm{Hb}, \mathrm{Ht}$ were at the onset of AMI. There was no significant difference between the two groups at the onset of AMI and any timing of follow-up. No patients had polycythemia in the present study.

\section{DISCUSSION}

In the present study, anterior AMI patients with the administration of a single dose of $12,000 \mathrm{IU}$ EPO after PCI had a tendency of smaller transmural extent of infarction in the acute phase. To the best of our knowledge, we have demonstrated for the first time a favorable effect of EPO on CMD and LA remodeling in the chronic phase of anterior AMI.

\section{Comparison with Other Clinical Trials}

EPO has been shown to protect various tissues submitted to ischemia-reperfusion in animal models, such as the brain, the retina, and the kidneys [4-6]. Several studies have also shown that administration of EPO during prolonged ischemia, or at the time of reperfusion, reduces infarct size and improves cardiac function in animal models of reperfused AMI [7, 8].

On the other hand, two recent clinical trials that have a significant sample size have shown negative or inconclusive results in regard to the safety and efficacy of EPO in patients with AMI $[10,11]$. The randomized, double-blind, placebo-controlled REVIVAL trial showed that short-term high-dose EPO $(60,000 \mathrm{IU}$ of epoetin 


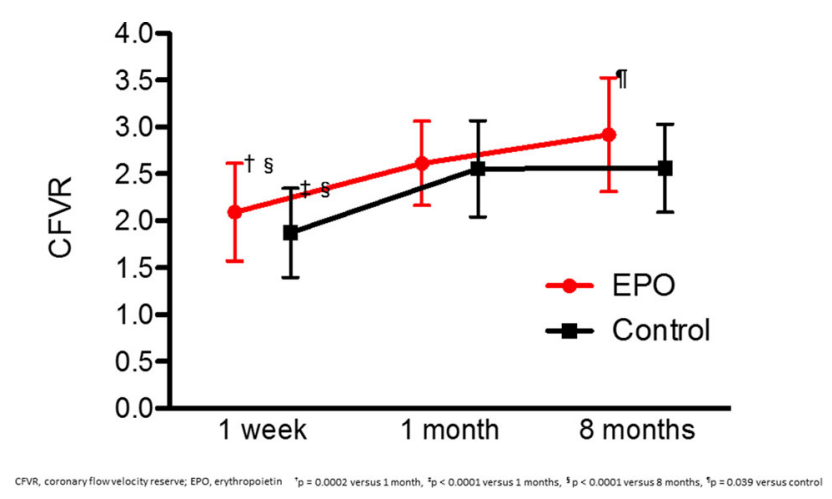

Fig. 1 Serial changes in coronary flow velocity reserve (CFVR). CFVR at 1 and 8 months after AMI was significantly higher than those at 1 week in EPO and control groups. CFVR at 8 months after AMI was significantly higher in EPO group compared with control group. CFVR coronary flow velocity reserve, EPO erythropoietin

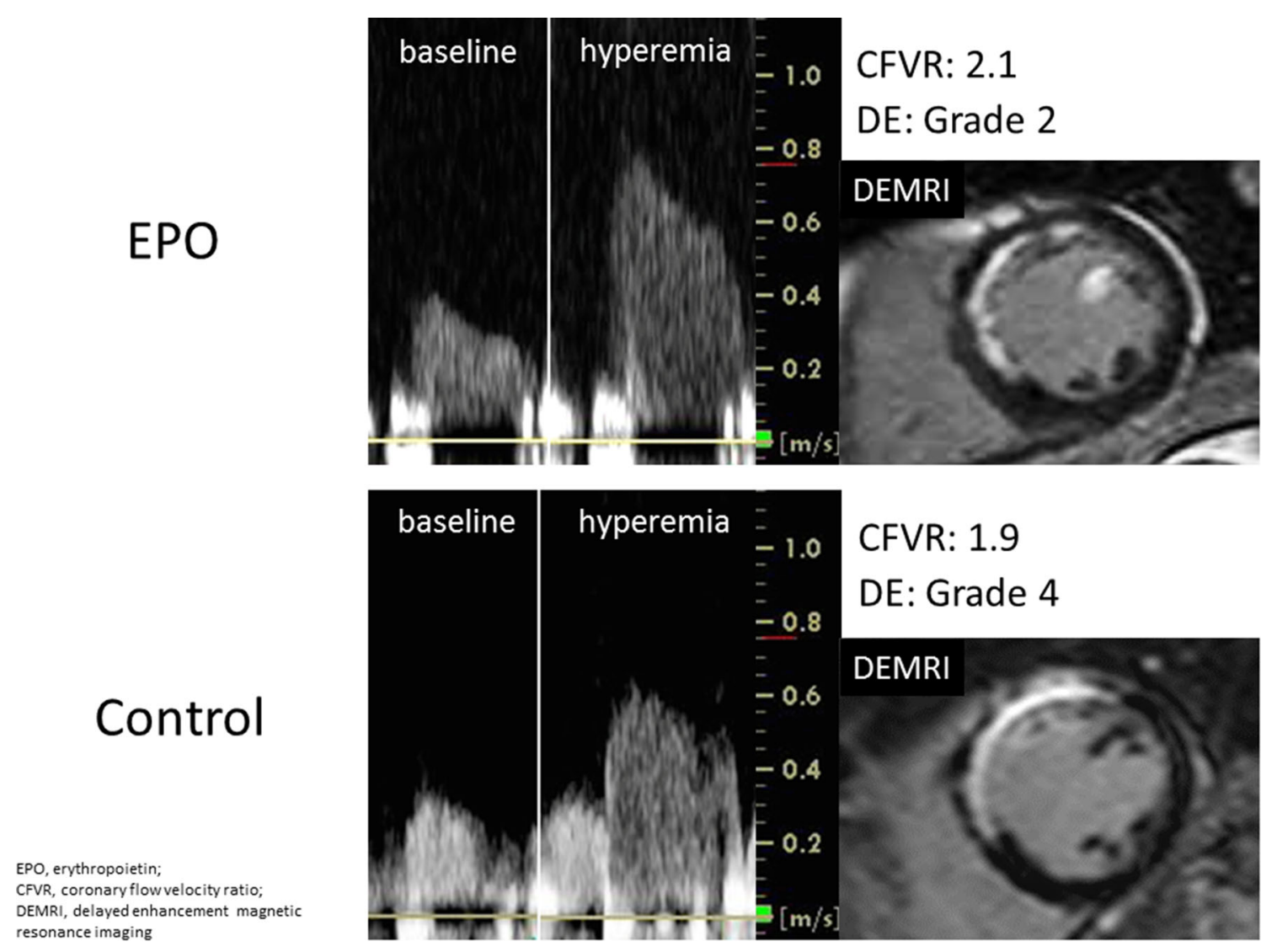

Fig. 2 Representative CFVR and delayed-enhanced cardiac magnetic resonance imaging (DEMRI) images. CFVR at 8 months and DEMRI at 1 week after AMI in patients with and without the administration of EPO. EPO erythropoietin, CFVR coronary flow velocity ratio, $D E M R I$ delayed enhancement magnetic resonance imaging 

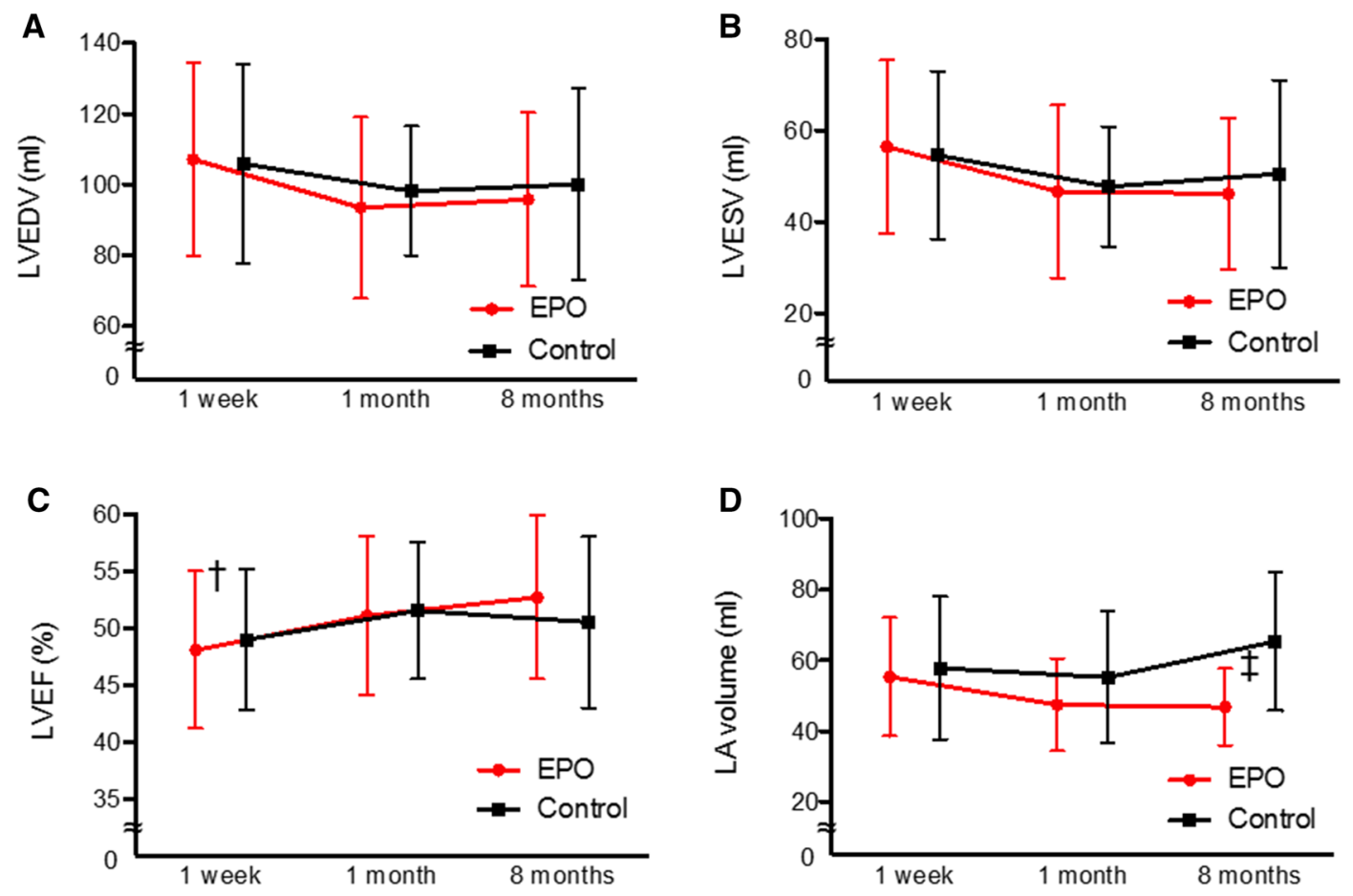

LVEDV, left ventricular end-diastolic volume; LVESV, LV end-systolic volume; LVEF, LV ejection fraction; LA, left atrial $p p=0.041$ versus 8 months, ${ }^{7} p=0.0002$ versus control

Fig. 3 Serial changes in cardiac remodeling. a LVEDV, b LVESV, c LVEF, d LA volume. In EPO group, LVEF at 8 months after AMI was significantly higher than those at 1 week (c). LA volume at 8 months after AMI was

alfa) in timely reperfused myocardium does not reduce infarct size and does not improve LVEF [10]. Small areas at risk in these clinical trials might be an issue for not showing an EPO beneficiary effect on the primary endpoint. Anterior AMI is more strongly affected by ischemia-reperfusion injury simply because it perfuses a larger myocardial territory. While the proportion of the patients with an occluded LAD were 27.6 and $40.9 \%$ in two clinical trials, we included the patients that occluded only LAD $[10,11]$. Another clinical trial reported that EPO administration significantly improved LVEF in the LAD subgroup, although no significant difference was observed in direct comparisons of the EPO and control group [17].

The REVIVAL trial also raised safety concerns due to a trend towards a higher incidence of adverse clinical events as well as an increase in neointima formation after treatment with EPO [10]. A high dose of EPO may induce significantly lower in EPO group than those of control group (d). $L V E D V$ left ventricular end-diastolic volume, $L V E S V \mathrm{LV}$ end-systolic volume, LVEF LV ejection fraction, $L A$ left atrial

thrombocytosis and platelet activation, which increases the risk of thrombosis and cardiovascular events as a result. On the other hand, a single medium dose (12,000 IU) of recombinant human EPO has been widely used for dialysis patients safely. A single dose of 12,000 IU EPO did not promote polycythemia in a past human study [17]. In the present study, we adopted a single dose of 12,000 IU EPO to avoid possible promotion of vascular events in the brain and heart. Therefore, our results indicate that the current safety concerns about EPO could not be translated to single medium dose administration in AMI patients treated with primary PCI.

\section{Cardioprotective Effect of EPO in AMI}

There are two possible mechanisms to explain the cardioprotective effects of EPO. Firstly, stimulation of the EPO receptor in the heart 
augments neovascularization through the increase of VEGF and endothelial progenitor cells homing to the myocardium [18]. Secondly, EPO has suppressive effects on apoptosis in ischemia-reperfusion models, potentially leading to smaller infarct sizes $[7,8,19]$. In the present study, there was no significant difference in VEGF, incidence of MVO, and CFVR at 1 week after ant AMI between two groups. On the other hand, transmural extent of infarction had a tendency to be smaller in the EPO group. A strong correlation between the transmural extent of infarction and the recovery of regional function after AMI has been described [20]. Indeed, time-dependent improvement of LVEF was observed only in the EPO group. Furthermore, CFVR at 8 months after AMI in EPO group was significantly higher than that of the control group.

CFVR is affected by the functional status of the distal microvascular bed in the absence of obstructive coronary artery narrowing and depends on multiple factors, including metabolic demands, myocardial resistance, filling pressures, neurohormonal activation, and vascular resistance of large and small coronary arteries [21]. Some studies have indicated that CFVR in the LAD using transthoracic Doppler echocardiography accurately reflects invasive measurement using Doppler guide wire $[22,23]$. Previous studies have reported that regional LV dysfunction correlated with impaired CFVR [24]. Doppler flow studies with serial measurements of coronary flow observed an increase in CFVR, indicating recovery of myocardial microcirculation [25]. Others also reported that improvement in CFVR was noted earlier than recovery of LV systolic dysfunction [26]. In the present study, improvement in CFVR correlated with the recovery of $\mathrm{LV}$ systolic dysfunction in both groups. Although there was no significant difference in LVEF between the two groups in each time point, time-dependent improvement of LVEF was observed only in EPO group. Moreover, a single medium dose of EPO had a preventive effect on LA remodeling in chronic phase of anterior AMI. LA remodeling is an independent predictor of death or heart failure hospitalization after AMI [27]. Furthermore, changes in LA size are related to worsening in increasing in LV volumes [28].

In the present study, small transmural extent of infarction may contribute to improve CMD in the chronic phase. Several studies have shown that CMD assessed by CFVR can predict cardiac remodeling, and long-term cardiovascular events in AMI $[13,21]$. Indeed, improvement of CMD in the EPO group may prevent LA remodeling in this study.

\section{Limitations}

Our study has several limitations. First, the study did not provide the etiology of the improvement of transmural extent of infarction and CFVR. We did not provide the markers of apoptosis, inflammation, and fibrosis in each time point. Secondly, the study did not provide the findings of non-LAD AMI. Further studies are needed to compare LAD and non-LAD AMI using our protocol. Third, the data of our study were not the latest. Our study was completed in September of 2014. Finally, the study did not provide the clinical relevance. However, EPO could have a favorable effect on infarct size in the acute phase and on LA remodeling in the chronic phase of anterior AMI. Further studies are needed to assess the clinical endpoint in adequate sample size or the effectiveness of EPO in patients in poor condition such as heart failure.

\section{CONCLUSIONS}

In this prospective, randomized, single-blind, placebo-controlled trial, a single medium dose of EPO could have a favorable effect on CMD and LA remodeling in the chronic phase of anterior AMI. Our data suggest that a single medium dose of EPO administration would be a promising treatment for anterior AMI.

\section{ACKNOWLEDGEMENTS}

We thank the participants of the study. 
Funding. No funding or sponsorship was received for this study or publication of this article. The article processing charges were funded by the authors.

Authorship. All named authors meet the International Committee of Medical Journal Editors (ICMJE) criteria for authorship for this article, take responsibility for the integrity of the work as a whole, and have given their approval for this version to be published.

Disclosures. Makoto Orii, Kumiko Hirata, Kazushi Takemoto, and Takashi Akasaka have nothing to disclose.

Compliance with Ethics Guidelines. All procedures performed in studies involving human participants were in accordance with the institutional ethics committee of Wakayama Medical University and with the 1964 Helsinki Declaration and its later amendments or comparable ethical standards. Informed consent was obtained from all individual participants included in the study.

Data Availability. The datasets during and/ or analyzed during the current study are available from the corresponding author on reasonable request.

Open Access. This article is distributed under the terms of the Creative Commons Attribution-NonCommercial 4.0 International License (http://creativecommons.org/licenses/ by-nc/4.0/), which permits any noncommercial use, distribution, and reproduction in any medium, provided you give appropriate credit to the original author(s) and the source, provide a link to the Creative Commons license, and indicate if changes were made.

\section{REFERENCES}

1. Sabia P, Afrookteh A, Touchstone DA, Keller MW, Esquivel L, Kaul S. Value of regional wall motion abnormality in the emergency room diagnosis of acute myocardial infarction: a prospective study using two dimensional echocardiography. Circulation. 1991;84:I85-92.

2. Gaudron P, Eilles C, Kugler I, Ertl G. Progressive left ventricular dysfunction and remodeling after myocardial infarction: potential mechanisms and early predictors. Circulation. 1993;87:755-63.

3. Hirsch A, Nijveldt R, Haeck JD, Beek AM, Koch KT, Henriques JP, van der Schaaf RJ, Vis MM, Baan J Jr, de Winter RJ, Tijssen JG, van Rossum AC, Piek JJ. Relation between the assessment of microvascular injury by cardiovascular magnetic resonance and coronary Doppler flow velocity measurements in patients with acute anterior wall myocardial infarction. J Am Coll Cardiol. 2008;10(51):2230-8.

4. Ruscher K, Freyer D, Karsch M, Isaev N, Megow D, Sawitzki B, Priller J, Dirnagl U, Meisel A. Erythropoietin is a paracrine mediator of ischemic tolerance in the brain: evidence from an in vitro model. J Neurosci. 2002;22:10291-301.

5. Grimm C, Wenzel A, Groszer M, Mayser H, Seeliger M, Samardzija M, Bauer C, Gassmann M, Remé CE. HIF-1-induced erythropoietin in the hypoxic retina protects against light-induced retinal degeneration. Nat Med. 2002;8:718-24.

6. Patel NS, Sharples EJ, Cuzzocrea S, Chatterjee PK, Britti D, Yaqoob MM, Thiemermann C. Pretreatment with EPO reduces the injury and dysfunction caused by ischemia/reperfusion in the mouse kidney in vivo. Kidney Int. 2004;66:983-9.

7. Parsa CJ, Matsumoto A, Kim J, Riel RU, Pascal LS, Walton GB, Thompson RB, Petrofski JA, Annex BH, Stamler JS, Koch WJ. A novel protective effect of erythropoietin in the infarcted heart. J Clin Invest. 2003;112:999-1007.

8. van der Meer P, Lipsic E, Henning RH, de Boer RA, Suurmeijer AJ, van Veldhuisen DJ, van Gilst WH. Erythropoetin improves left ventricular function and coronary flow in an experimental model of ischemia-reperfusion injury. Eur $\mathrm{J}$ Heart Fail. 2004;6:853-9.

9. Hirata A, Minamino $T$, Asanuma $H$, Fujita $M$, Wakeno M, Myoishi M, Tsukamoto O, Okada K, Koyama H, Komamura K, Takashima S, Shinozaki Y, Mori H, Shiraga M, Kitakaze M, Hori M. Erythropoietin enhances neovascularization of ischemic myocardium and improves left ventricular dysfunction after myocardial infarction in dogs. J Am Coll Cardiol. 2006;48:176-84.

10. Najjar SS, Rao SV, Melloni C, Raman SV, Povsic TJ, Melton L, Barsness GW, Prather K, Heitner JF, Kilaru R, Gruberg L, Hasselblad V, Greenbaum AB, Patel M, Kim RJ, Talan M, Ferrucci L, Longo DL, Lakatta EG, Harrington RA; REVEAL Investigators. 
Intravenous erythropoietin in patients with STsegment elevation myocardial infarction: REVEAL: a randomized controlled trial. JAMA. 2011;305:1863-1872.

11. Voors AA, Belonje AM, Zijlstra F, Hillege HL, Anker SD, Slart RH, Tio RA, van 't Hof A, Jukema JW, Peels HO, Henriques JP, Ten Berg JM, Vos J, van Gilst $\mathrm{WH}$, van Veldhuisen DJ, HEBE III Investigators. A single dose of erythropoietin in ST-elevation myocardial infarction. Eur Heart J. 2010;31:2593-2600.

12. Takemoto K, Hirata K, Wada N, Shiono Y, Komukai $\mathrm{K}$, Tanimoto $\mathrm{T}$, Ino $\mathrm{Y}$, Kitabata $\mathrm{H}$, Takarada $\mathrm{S}$, Nakamura N, Kubo T, Tanaka A, Imanishi T, Akasaka T. Acceleration time of systolic coronary flow velocity to diagnose coronary stenosis in patients with microvascular dysfunction. J Am Soc Echocardiogr. 2014;27:200-7.

13. Nakanishi K, Fukuda S, Shimada K, Miyazaki C, Otsuka K, Maeda K, Miyahana R, Kawarabayashi T, Watanabe H, Yoshikawa J, Yoshiyama M. Impaired coronary flow reserve as a marker of microvascular dysfunction to predict long-term cardiovascular outcomes, acute coronary syndrome and the development of heart failure. Circ J. 2012;76:1958-64.

14. Orii $\mathrm{M}$, Hirata $\mathrm{K}$, Tanimoto $\mathrm{T}$, Ota $\mathrm{S}$, Shiono $\mathrm{Y}$, Yamano T, Matsuo Y, Ino Y, Yamaguchi T, Kubo T, Tanaka A, Akasaka T. Comparison of cardiac MRI and 18F-FDG positron emission tomography manifestations and regional response to corticosteroid therapy in newly diagnosed cardiac sarcoidosis with complete heart block. Heart Rhythm. 2015;12:2477-85.

15. Bondarenko O, Beek AM, Hofman MB, Kühl HP, Twisk JW, van Dockum WG, Visser CA, van Rossum AC. Standardizing the definition of hyperenhancement in the quantitative assessment of infarct size and myocardial viability using delayed contrastenhanced CMR. J Cardiovasc Magn Reson. $2005 ; 7: 481-5$.

16. Kim RJ, Wu E, Rafael A, Chen EL, Parker MA, Simonetti O, Klocke FJ, Bonow RO, Judd RM. The use of contrast-enhanced magnetic resonance imaging to identify reversible myocardial dysfunction. N Engl J Med. 2000;343:1445-53.

17. Ozawa T, Toba K, Suzuki H, Kato K, Iso Y, Akutsu Y, Kobayashi Y, Takeyama Y, Kobayashi N, Yoshimura N, Akazawa K, Aizawa Y; EPO/AMI-I Pilot Study Researchers. Single-dose intravenous administration of recombinant human erythropoietin is a promising treatment for patients with acute myocardial infarction-randomized controlled pilot trial of EPO/AMI-1 study. Circ J. 2010;74:1415-1423.
18. Westenbrink BD, Lipsic E, van der Meer $\mathrm{P}$, van der Harst P, Oeseburg H, Du Marchie Sarvaas GJ, Koster J, Voors AA, van Veldhuisen DJ, van Gilst WH, Schoemaker RG. Erythropoietin improves cardiac function through endothelial progenitor cell and vascular endothelial growth factor mediated neovascularization. Eur Heart J. 2007;28:2018-27.

19. Pessoa FG, Mady C, Fonseca KCB, de Oliveira-Fonoff AM, Salemi VMC, Jordão MR Fernandes F, Ramires FJA. Erythropoietin reduces collagen deposition after myocardial infarction but does not improve cardiac function. Can J Physiol Pharmacol. 2017. https://doi.org/10.1139/cjpp-2017-0169.

20. Beek AM, Kühl HP, Bondarenko O, Twisk JW, Hofman MB, van Dockum WG, Visser CA, van Rossum AC. Delayed contrast-enhanced magnetic resonance imaging for the prediction of regional functional improvement after acute myocardial infarction. J Am Coll Cardiol. 2003;42:895-901.

21. Bax M, de Winter RJ, Schotborgh CE, Koch KT, Meuwissen M, Voskuil M, Adams R, Mulder KJ, Tijssen JG, Piek JJ. Short- and long-term recovery of left ventricular function predicted at the time of primary percutaneous coronary intervention in anterior myocardial infarction. J Am Coll Cardiol. 2004;43:534-41.

22. Hozumi T, Yoshida K, Akasaka T, Asami Y, Ogata Y, Takagi T, Kaji S, Kawamoto T, Ueda Y, Morioka S. Noninvasive assessment of coronary flow velocity and coronary flow velocity reserve in the left anterior descending coronary artery by Doppler echocardiography: comparison with invasive technique. J Am Coll Cardiol. 1998;32:1251-9.

23. Gadallah S, Thaker KB, Kawanishi D, Mehra A, Lau S, Rashtian M, Chandraratna AN. Comparison of intracoronary Doppler guide wire and transesophageal echocardiography in measurement of flow velocity and coronary flow reserve in the left anterior descending coronary artery. Am Heart J. 1998;135:38-42.

24. Rosen BD, Lima JA, Nasir K, Edvardsen T, Folsom AR, Lai S, Bluemke DA, Jerosch-Herold M. Lower myocardial perfusion reserve is associated with decreased regional left ventricular function in asymptomatic participants of the multi-ethnic study of atherosclerosis. Circulation. 2006;114:289-97.

25. Lepper W, Sieswerda GT, Franke A, Heussen N, Kamp O, de Cock CC, Schwarz ER, Voci P, Visser CA, Hanrath P, Hoffmann R. Repeated assessment of coronary flow velocity pattern in patients with first acute myocardial infarction. J Am Coll Cardiol. 2002;39:1283-9. 
26. Sugioka K, Hozumi T, Takemoto Y, Ehara S, Ogawa $\mathrm{K}$, Iwata S, Oe H, Matsumura Y, Otsuka R, Yoshiyama $\mathrm{M}$, Yoshikawa J. Relation of early improvement in coronary flow reserve to late recovery of left ventricular function after beta-blocker therapy in patients with idiopathic dilated cardiomyopathy. Am Heart J. 2007;153(1080):e1-6.

27. Meris A, Amigoni M, Uno H, Thune JJ, Verma A, Køber L, Bourgoun M, McMurray JJ, Velazquez EJ, Maggioni AP, Ghali J, Arnold JM, Zelenkofske S,
Pfeffer MA, Solomon SD. Left atrial remodelling in patients with myocardial infarction complicated by heart failure, left ventricular dysfunction, or both: the VALIANT Echo study. Eur Heart J. 2009;30:56-65.

28. Beinart R, Boyko V, Schwammenthal E, Kuperstein R, Sagie A, Hod H, Matetzky S, Behar S, Eldar M, Feinberg MS. Long-term prognostic significance of left atrial volume in acute myocardial infarction. J Am Coll Cardiol. 2004;44:327-34. 